\title{
Extreme group index measured and calculated in 2D SOI-based photonic crystal waveguides
}

Lavrinenko, Andrei; Jacobsen, Rune Shim; Fage-Pedersen, Jacob; Frandsen, Lars Hagedorn; Zsigri, Beata; Peucheret, Christophe; Borel, Peter Ingo

Published in:

The 18th Annual Meeting of the IEEE Lasers and Electro-Optics Society, 2005. LEOS 2005.

Link to article, DOI:

10.1109/LEOS.2005.1548008

Publication date:

2005

Document Version

Publisher's PDF, also known as Version of record

Link back to DTU Orbit

Citation $(A P A)$ :

Lavrinenko, A., Jacobsen, R. S., Fage-Pedersen, J., Frandsen, L. H., Zsigri, B., Peucheret, C., \& Borel, P. I. (2005). Extreme group index measured and calculated in 2D SOI-based photonic crystal waveguides. In The 18th Annual Meeting of the IEEE Lasers and Electro-Optics Society, 2005. LEOS 2005. IEEE.

https://doi.org/10.1109/LEOS.2005.1548008

\section{General rights}

Copyright and moral rights for the publications made accessible in the public portal are retained by the authors and/or other copyright owners and it is a condition of accessing publications that users recognise and abide by the legal requirements associated with these rights.

- Users may download and print one copy of any publication from the public portal for the purpose of private study or research.

- You may not further distribute the material or use it for any profit-making activity or commercial gain

- You may freely distribute the URL identifying the publication in the public portal 


\title{
Extreme group index measured and calculated in 2D SOI-based photonic crystal waveguides
}

\author{
Andrei V. Lavrinenko, Rune S. Jacobsen, Jacob Fage-Pedersen, Lars H. Frandsen, \\ Beata Zsigri, Christophe Peucheret, and Peter I. Borel \\ Research Center COM, NanoDTU, Technical University of Denmark, Building-345v, DK- \\ 2800, Kgs. Lyngby, Denmark, ala@,com.dtu.dk
}

It is generally accepted that so-called slow light, i.e. propagating modes having a group velocity $(\mathrm{GV})$ significantly smaller than the phase velocity in the bulk material, can contribute to the enhancement of light-matter interaction ${ }^{1-3}$. Recently, experimental investigations of slow light have been performed by several groups $\mathrm{s}^{4,5}$ and the interest in utilizing slow light properties is constantly increasing.

One of the main candidates for revealing slow light properties is a photonic crystal possessing strong nonlinear dispersion ${ }^{1-3}$. The optical modes of the photonic crystal are retarded in the regions of the flat dispersion bands causing a vanishing GV or put in another way - boosting the group index to very high values.

We have measured and calculated the GV dispersion in the proximity of the cutoff wavelength for the fundamental photonic bandgap mode in a $2 \mathrm{D}$ photonic crystal waveguide (PCW). The PCW is created by introducing a line defect in an otherwise perfect triangular lattice of air-holes in the 216-nm thick silicon layer in an SOI material. The silicon layer is covered with silica on top. The lattice pitch $\Lambda=425 \mathrm{~nm}$ and the hole diameter $d=272 \mathrm{~nm}$. Experimental transmission spectra show a mode cut-off around $1562.5 \mathrm{~nm}$ for the fundamental photonic bandgap mode.

In order to measure and model the group index of modes in the PCW, a time-offlight (ToF) method is applied.

The basic concept of measuring the change of the group index versus wavelength $\Delta n_{g}(\lambda)$ using the ToF method is to measure the phase delay of a transmitted signal as a function of wavelength. The transmitted signal is an envelope function for the amplitude of the light, and the phase velocity of the signal is, hence, identical to the group index for the light. In the experiment, a network analyzer is utilized at $19 \mathrm{GHz}$ to modulate the amplitude of an optical signal which is sent through a $20 \mu \mathrm{m}$ long PCW, and to record the phase of the transmitted signal. The measured phase gives the dispersion of the whole experimental setup. To obtain the phase change caused by the PCW alone, the data is normalized to (a third-order polynomial fit of) a reference measurement for a buried silicon waveguide that is located on the same sample but containing no PCW.

The measured change in group index as a function of wavelength is affected by traditional Fabry-Perot (F-P) cavities in the sample arising from, e.g., the sample facets and the interface between the PCW and the buried waveguides used for coupling light in and out of the PCW. To track down such F-P effects, a highresolution transmission spectrum was recorded and it revealed two main F-P cavities with periods of $0.14 \mathrm{~nm}$ and $0.7 \mathrm{~nm}$. The contribution of the F-P cavities to the change in group index was removed by averaging the transmitted signal, taking the F$\mathrm{P}$ periods into account.

The ToF method was applied in 3D finite-difference time-domain (FDTD) modeling using a spatial grid size $\delta=27 \mathrm{~nm}$. A TE-polarized pulse was launched from a ridge waveguide into the PCW. The pulse tracking was made by two detectors placed at the input and output ports of the PCW. By storing the fields in all time for 
both detectors we can restore the dynamics of the pulse propagation through the detectors. Recording the moments where the top of the impulse passes the detectors we can calculate the time delay $\Delta t$, which, together with the known distance between the detectors $\Delta L$, is used for computing the group index.

The experimental and calculated values of the group index are plotted in the figure. The calculated values have been shifted in wavelength to match the experimental curve. The deviation between the calculated and measured curve is due to uncertainties in the fundamental parameters of the fabricated sample and truncations of the structure needed in the modelling due to severe memory requirements of the method. However, it is evident that the calculated values of the group index are in very good agreement with the measured values. The FDTD calculation predicts not only the absolute level of the group index but also the index oscillations near the mode cutoff around $1562.5 \mathrm{~nm}$.

We obtained a large group index reaching 166 in 3D ToF modeling and up to 440 in $2 \mathrm{D}$ modeling. The experiments showed values up to 215 , which, to our best knowledge, are world-record values obtained by direct measurements.

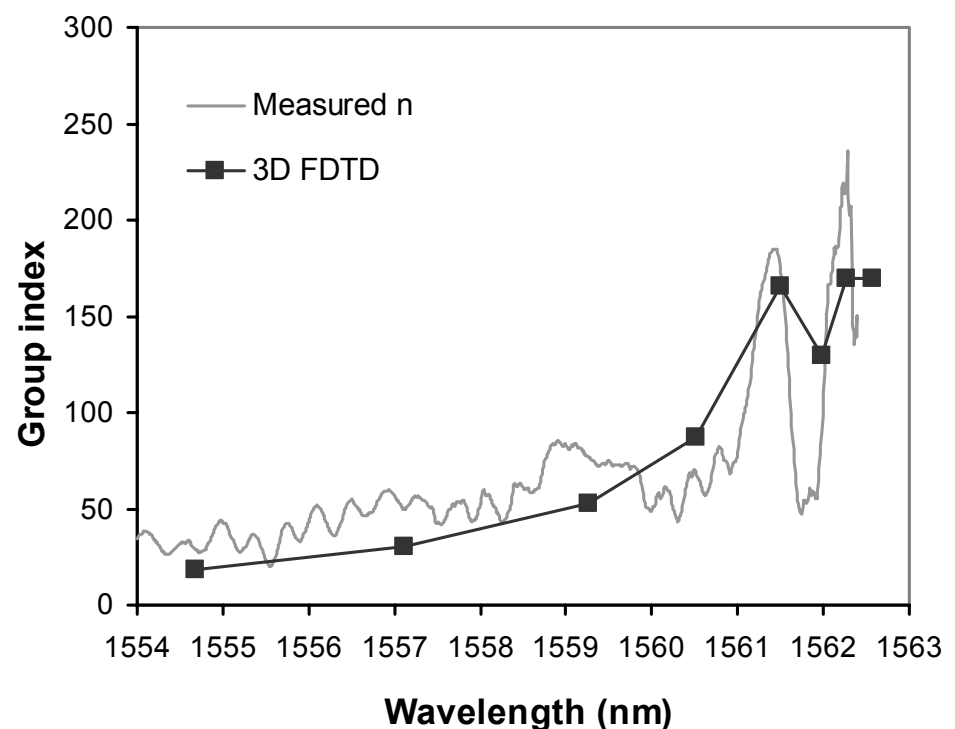

Figure: Measured and calculated group index as a function of wavelength.

\section{References}

1. M. Notomi, K. Yamada, A. Shinya, J. Takahashi, C. Takahashi, I. Yokohama, "Extremely large group-velocity dispersion of line-defect waveguides in photonic crystal slabs", Phys. Rev. Lett., 87, 253902, 2001.

2. M. Soljacic, J.D.Joannopoulos, "Enhancement of nonlinear effects using photonic crystals", Nature materials, 3, 211-219, 2004.

3. S. Inoue, Y. Aoyagi, "Design and fabrication of two-dimensional photonic crystals with predetermined nonlinear optical properties", Phys. Rev. Lett., 94, 103904, 2005.

4. Y. Chen, S. Blair, "Nonlinearity enhanced in finite coupled-resonator slow-light waveguides", Opt. Express, 12, 3353-3366, 2004.

5. J. Hwang, N.Y. Ha, H.J. Chang, B. Park, J.W. Wu, "Enhanced nonlinearity near the photonic band edges of a cholesteric liquid crystal", Opt. Lett, 29, 2644-2646, 2004. 